\title{
Análise das Competências Profissionais dos Gestores como suporte à Gestão de Pessoas nas Organizações
}

Maria Celeste Reis Lobo de Vasconcelos ${ }^{1}$

Juliana Oliveira Braga²

\section{Resumo}

O cenário competitivo no qual as organizações contemporâneas estão inseridas, leva-as a uma necessidade de desenvolvimento constante do seu corpo gerencial, para que possam acompanhar e mesmo antever e propiciar mudanças exigidas pelo contexto atual. Como conseqüência desta necessidade, vários autores têm se dedicado ao estudo e elaboração de modelos que possibilitem 0 desenvolvimento de competências profissionais e organizacionais.

Este artigo focaliza os resultados de uma pesquisa desenvolvida com o objetivo de identificar quais as competências existentes e as requeridas no trabalho dos gestores da Igreja Metodista, no desempenho das suas funções. A população estudada foi constituída pelos superintendentes distritais num total de 93 indivíduos, distribuídos em oito regiões do Brasil.

1 Doutora em Ciência da Informação - UFMG. Professora e Vice Coordenadora do Curso de Mestrado Profissional em Administração da Fundação Pedro Leopoldo celestevasconcelos@terra.com.br

2 Mestranda MPA Fundação Pedro Leopoldo. Professora Unicentro Newton Paiva juolive@uai.com.br 
A análise focalizou o trabalho das equipes regionais de superintendentes distritais, bem como a sua relação com os seus respectivos pastores. $O$ resultado da análise das competências profissionais dos superintendentes, frente ao modelo adotado, servirá como indutor para discussões e reflexões sobre possíveis programas de treinamento gerencial.

Palavras-chave: competência, capital intelectual, aprendizagem organizacional, gestão do conhecimento

\section{Introdução}

No ambiente atual das organizações, percebe-se uma lacuna entre a formação tradicional dos gestores e as competências esperadas destes para a sua gestão. Esperase que os gestores sejam capazes de desempenhar múltiplos papéis de forma a atender as demandas crescentes de um mercado bastante dinâmico e agregar valor às organizações, tudo isto num ambiente de interação, de articulação e de ênfase na aprendizagem coletiva.

Observa-se que as tradicionais práticas de treinamento e desenvolvimento parecem não responder mais as novas demandas organizacionais. Segundo RUAS (2001), as propostas de formação e treinamento que seriam responsáveis por desencadear padrões de performance e desempenho não estão colaborando para o desenvolvimento de competências.

De acordo com o autor, acaba-se por estabelecer um "gap" entre os conteúdos, experiências e vivências exploradas nos programas de formação e treinamento e o processo de transformação destes recursos em competências.

Como conseqüência da necessidade de aumentar a eficiência dos programas de treinamento e formar gestores com as competências exigidas pelo mercado, vários autores têm se dedicado ao estudo e elaboração de modelos que possibilitem o desenvolvimento de competências profissionais e organizacionais. BARBOSA (2001) afirma que a construção destes modelos com base nas competências tem surgido como possibilidade concreta de obter ganhos organizacionais, bem como de recompensar os esforços individuais.

Neste contexto de avaliação e reflexão sobre os modelos tradicionais de gestão, também se insere a Igreja Metodista. Embora não seja considerada uma empresa, a Igreja Metodista vive este ambiente de busca de novos modelos de gestão, pois, sendo uma instituição que vive dentro e para a sociedade, ela sofre todos os impactos globais pelos quais o mundo vem passando.

Percebe-se a necessidade de líderes religiosos capazes e competentes para fazerem cumprir a missão da Igreja e que não se deixem levar pela magia, misticismo, afetando a verdadeira natureza da Igreja e o sentido da fé.

Faz-se necessário compreender o processo de mudanças das organizações, do profissional exigido para agir dentro deste contexto, para que possa estabelecer programas com o objetivo de desenvolver líderes mais adaptáveis e flexíveis à nova realidade organizacional. O que se pretende, em última instância, é a melhor adequação das pessoas às atuais exigências do mundo do trabalho. 
Este artigo focaliza os resultados de uma pesquisa desenvolvida com o objetivo de identificar quais as competências existentes e as requeridas no trabalho dos gestores da Igreja Metodista, no desempenho das suas funções. O modelo utilizado para análise foi o de competências profissionais de FLEURY \& FLEURY (2001) composto pelas sete variáveis: saber agir, saber mobilizar, saber comunicar, saber aprender, saber comprometer-se, saber assumir responsabilidades e ter visão estratégica.

Para o alcance do objetivo final, foram traçados alguns objetivos intermediários que foram: descrever a instituição pesquisada, procurando recuperar sua origem, sua história, sua forma de organização, seu estilo de governo, sua missão e sua atuação no Brasil; definir as competências que são esperadas dos gestores das organizações contemporâneas, segundo a literatura; analisar os gestores da Igreja Metodista segundo estas competências e sugerir melhorias que possam contribuir, para o exercício da superintendência distrital da Igreja Metodista, com base nos resultados da pesquisa.

A população estudada foi constituída pelos superintendentes distritais num total de 93 indivíduos, distribuídos em 8 regiões do Brasil. A análise focalizou o trabalho das equipes regionais de superintendentes distritais, bem como a sua relação com os seus respectivos pastores.

\section{A Igreja Metodista no Brasil}

A Igreja Metodista iniciou suas atividades na Inglaterra, no século XVIII, como um movimento de renovação espiritual. João Wesley era um pastor da Igreja Anglicana que, tendo uma vida metódica desde a sua mocidade, trazia consigo, ainda quando estudante na Universidade de Oxford, uma grande inquietação de natureza pessoal. Wesley dedicou-se a viajar pelo país evangelizando, treinando pregadores leigos e líderes para as classes, escrevendo livros e manuais para a instrução sobre a Bíblia e a fé cristã.

Partindo da Inglaterra, o movimento metodista foi para as colônias da América do Norte, onde prosperou, organizando-se como Igreja Metodista antes mesmo da Inglaterra. Foi no início do século XIX que a Igreja Metodista passou a se expandir por diversos países do mundo, por meio dos missionários enviados pela Igreja Americana. Contudo, só no ano de 1867, por intermédio das famílias metodistas vindas do sul dos Estados Unidos que a Igreja Metodista se instalou definitivamente em território brasileiro.

A Igreja Metodista está hoje organizada em seis regiões eclesiásticas, uma região missionária e um campo missionário. A Primeira Região reúne as Igrejas do Estado do Rio de Janeiro. A Segunda Região fica no Rio Grande do Sul. A Terceira Região compreende as igrejas da cidade de São Paulo e arredores, Baixada Santista e Vale do Paraíba. A Quarta Região abrange as igrejas de Minas (exceto sul de Minas e Triângulo) e Espírito Santo. A Quinta Região é formada pelas cidades do interior de São Paulo, Sul de Minas, Triângulo Mineiro, Goiás, Distrito Federal, Mato Grosso do Sul e Tocantins. A Sexta Região situa-se nos estados do Paraná e Santa Catarina. As Igrejas Metodistas nos estados do nordeste da Bahia até o Piauí formam a Região Missionária do Nordeste. Os Campos Missionários compreendem os estados da região Amazônica (Amazonas, Rondônia, Roraima. Acre, Pará, Amapá e Maranhão). 
A missão da Igreja Metodista é participar da ação de Deus no seu propósito de salvar o mundo. Sua forma de governo é episcopal, encargo de serviço especial, a partir da eleição de alguns presbíteros para exercerem esta função e seu sistema representativo. (CÂNONES, 2001).

\section{Conceito de Competência}

Os primeiros estudos sobre competências destacam-se com McClelland, no início da década de 70, nos quais ele afirmava que os testes tradicionais de conhecimento e inteligência utilizados em seleção não eram capazes de prognosticar o desempenho do candidato no trabalho e na vida e por sua vez, predispunha preconceitos contra as minorias que eram as mulheres e pessoas de nível sócio econômico inferior.

Sendo assim, McClelland voltou-se para a busca de métodos de avaliação que possibilitassem identificar com mais eficácia variáveis de competência capazes de prognosticar êxito no trabalho e na vida. Seus resultados identificaram diferenças de habilidades, aptidões e atitudes, o que o fez indicar um novo modelo de competência, encontrando novos métodos e critérios de seleção e diminuindo a relevância do perfil intelectual e da formação acadêmica. (GARCIA, 2001).

De acordo com ZARIFIAN (2001), o desenvolvimento do conceito de competência surge atrelado a mudança do conceito de trabalho. O modelo de trabalho da era industrial concebia uma separação entre trabalho e trabalhador. "O trabalho é definido como um conjunto de operações elementares de transformação da matéria que se pode objetivar, descrever, analisar, racionalizar, organizar e impor nas oficinas" (ZARIFIAN, 1996:37). O trabalhador era considerado como um conjunto de capacidades que poderiam ser compradas no mercado de trabalho para realizar parte das operações. e era visto, simplesmente, como uma força de trabalho.

Segundo HIRATA (1994), a noção de competência surge como um compromisso pós-taylorista, de uma superação do paradigma da polarização das qualificações e a adoção de novas condições de organização do trabalho e de gestão da produção. Contudo, ZARIFIAN (1996:42) aponta mutações no conteúdo do trabalho, que acabam por ampliar esta visão separativista do conceito de trabalho e trabalhador. Estas mutações ocorrem em torno de três aspectos: o evento, a comunicação e o serviço.

O conceito de trabalho volta ao trabalhador, não podendo mais separar trabalho e trabalhador. "O trabalho é a ação competente do indivíduo diante de uma situação de evento". Desta maneira, a competência profissional não poderia mais ser previamente definida. Trabalhar significaria assim, estar atento aos eventos, pressenti-los, dominá-los e enfrentá-los com sucesso de modo a atingir os resultados esperados.

Da mesma forma, ZARIFIAN (1996) afirma que a discussão sobre competência surgiu na França ligada à crise do modelo taylorista e burocrática do trabalho. Modelo este que definia previamente as capacidades que um indivíduo deveria possuir para ocupar um posto de trabalho. No início dos anos oitenta, as organizações que tentavam sair da crise econômica de uma maneira positiva, buscaram elevar a qualidade e diversidade de seus produtos e aumentar as inovações.

Estas organizações utilizaram estratégias que visavam a atender o aumento da complexidade do trabalho e um aumento do tratamento da confrontação aos eventos 
sobre o respeito à normas rotineiras. ZARIFIAN (1994) define competência "como uma inteligência prática de situações que se apóiam nos conhecimentos adquiridos e os transformam, com quanto mais força, quanto mais aumenta a complexidade das situações". O autor justifica o surgimento do modelo de competência para a gestão das organizações, devido a três razões principais que provocam a inconstância no mundo do trabalho:

- noção de incidente, o que ocorre de maneira imprevista, não programada, causa alteração no processo habitual do sistema de produção, que transpõe a capacidade do equilíbrio homeostático, sendo assim, isto pressupõe que a competência não pode estar definida e atrelada ao cargo e/ou nas tarefas, o trabalhador necessita sempre mobilizar novos recursos para resolver situações até então desconhecidas no ambiente de trabalho; - a comunicação, compreender o outro e a si mesmo, entrar em consonância com os objetivos organizacionais e compartilhar normas comuns;

- os serviços, vêm da habilidade da comunicação, noção de atender a um cliente externo ou interno à organização.

Sendo assim, ZARIFIAN (1996) conceitua a competência como um "assumir de responsabilidade pessoal do assalariado frente às situações produtivas", por meio do exercício sistemático de uma atitude reflexiva face ao trabalho. O indivíduo por si mesmo, tentando mobilizar e atingir o complexo de performances para enfrentar os eventos que ocorrem de forma imprevista na situação produtiva. A reflexividade no trabalho exige um posicionamento crítico, um questionamento do indivíduo da maneira de trabalhar.

Para a ocorrência do desenvolvimento da reflexividade é preciso considerar a dimensão cognitiva e ainda ressaltar três condições específicas que visam esta prática: $O$ autor ainda afirma que desenvolver competências, é, antes de tudo, criar as melhores condições possíveis para que os trabalhadores possam assumir responsabilidades e se mobilizar subjetivamente. Implica, assim, a delegação por parte dos superiores hierárquicos, de uma parte de suas responsabilidades.

FLEURY \& FLEURY (2001) estabelecem uma proposta de desenvolvimento de novas competências para os gestores, assumindo o movimento das mudanças e contextualizando os processos atuais, por meio da identificação dos atores envolvidos, seus objetivos, processos de interação e os indicadores de performance. Os autores acreditam que a construção deste conceito perpassa pela análise das estratégias que definem as competências e por sua vez estas vão refletir na escolha das estratégias por meio do processo de aprendizagem.

Os autores citam MCLAGAN (1997:41) que ressalta que competência pode ser usada como uma palavra do senso comum, utilizada para designar pessoa qualificada para determinado fim. No mundo do trabalho, competência assume significados ligados às características das pessoas: conhecimentos, habilidades, atitudes e outros à tarefa: resultados.

ZARIFIAN (1994:111) considera que o conceito de competência vai além do conceito de qualificação pois, refere-se à capacidade do indivíduo de assumir iniciativas, ultrapassar o estabelecido, ser capaz de compreender e identificar novas situações no trabalho, ser responsável e ser valorizado por isto.

Portanto, o conceito de competência não se limita aos conhecimentos teóricos e empíricos retidos pelas pessoas e nem se encontra preso na tarefa, ao contrário da qualificação que é determinada pela posição, ou ao cargo, ou pelos conhecimentos da 
pessoa aferidos pelo sistema educacional. $O$ trabalho passa a ser uma extensão direta da competência do indivíduo, da dinâmica que estabelece em face de contextos profissionais cada vez mais mutáveis e complexos.

LE BOTERF (1994) citado por FLEURY \& FLEURY (2001: 20) conceitua competência com três elementos formadores: pessoa (biografia, socialização), formação educacional e experiência profissional. O autor afirma que a competência advém de aprendizagens sociais comunicacionais alimentada de um lado pela aprendizagem e formação e de outro pelo sistema de avaliação.

“Competência é um saber agir responsável e que é reconhecido pelos outros. Implica saber como mobilizar, integrar e transferir os conhecimentos, recursos e habilidades, num contexto profissional determinado". (Pág. 20)

\section{Competências do Profissional}

FLEURY \& FLEURY (2001:21) se dedicaram à análise das competências do profissional e definem competência como: "Saber agir responsável e reconhecido, que implica mobilizar, integrar, transferir conhecimentos, recursos, habilidades, que agreguem valor econômico à organização e valor social ao indivíduo".

Os autores definem um modelo de competências profissionais com sete variáveis, que são: saber agir, saber mobilizar, saber comunicar, saber aprender, saber comprometer-se, saber assumir responsabilidades e ter visão estratégica. A Tab. 1 define estes termos.

\section{TABELA 1}

\begin{tabular}{|c|c|}
\hline \multicolumn{2}{|r|}{ Competências do Profissional } \\
\hline Saber agir & $\begin{array}{l}\text { - Saber o que e por que faz. } \\
\text { - Saber julgar, escolher, decidir. }\end{array}$ \\
\hline Saber $n$ & $\begin{array}{l}\text { - Saber mobilizar recursos de pessoas, financeiros, } \\
\text { materiais, criando sinergia entre eles. }\end{array}$ \\
\hline Saber c & $\begin{array}{l}\text { - Compreender, processar, transmitir informações e } \\
\begin{array}{l}\text { conhecimentos, assegurando o entendimento da } \\
\text { mensagem pelos outros. }\end{array}\end{array}$ \\
\hline Saber a & $\begin{array}{l}\text { - Trabalhar o conhecimento e a experiência. } \\
\text { - Rever modelos mentais. } \\
\text { - Saber desenvolver-se e propiciar o desenvolvimento } \\
\text { dos outros. }\end{array}$ \\
\hline $\begin{array}{l}\text { Saber comprometer- } \\
\text { se }\end{array}$ & $\begin{array}{l}\text { - Saber engajar-se e comprometer-se com os objetivos } \\
\text { da organização. }\end{array}$ \\
\hline $\begin{array}{l}\text { Saber assumir } \\
\text { responsabilidades }\end{array}$ & $\begin{array}{l}\text { - Ser responsável, assumindo os riscos e as } \\
\text { conseqüências de suas ações, e ser, por isso, } \\
\text { reconhecido. }\end{array}$ \\
\hline Ter visão & $\begin{array}{l}\text { - Conhecer e entender o negócio da organização, seu } \\
\text { ambiente, identificando oportunidades, alternativas. }\end{array}$ \\
\hline
\end{tabular}

FONTE- FLEURY \& FLEURY (2001: 22) 
DUTRA (2001) corrobora com os conceitos de FLEURY \& FLEURY (2001) e afirma que a gestão de pessoas com base em competências surge a partir das mudanças sofridas nas últimas décadas, tais como: alteração no perfil das pessoas exigido pelas empresas; deslocamento do foco da gestão de pessoas por meio de controle para o foco no desenvolvimento das pessoas e pela intensificação da participação das pessoas no êxito da organização.

Estas transformações acabam por exigir novos desafios que visam retratar novas posturas e práticas no gerenciamento de pessoas. Para o autor, existe uma relação íntima entre as competências organizacionais e as individuais. Ocorre um processo de troca de competências, no qual a empresa transfere seu patrimônio de conhecimento para as pessoas e estas, por sua vez, ao desenvolverem seu potencial individual, revertem para a organização seu aprendizado, garantindo o seu diferencial competitivo.

RUAS (2001) repensa o conceito de competência e o coloca de uma forma dinâmica, em uma forma de ação. Novas estratégias envolvem mudanças na forma de pensar e atuar. Estas mudanças podem ser profundas ou não. Contudo, antes de qualquer coisa passam pela mudança individual do gestor.

"Parece não haver dúvida acerca da importância do papel gerencial no processo de mudança, especialmente no que concerne a tarefa de internalizá-la no ambiente organizacional. Por outro lado, a direção desse processo de internalização vai exigir do gestor disposição e capacidade de mudar a si próprio" (RUAS, 2001:247).

RUAS (2001) aponta três dimensões para a formação de competências. A primeira dimensão, corroborando com PRAHALAD \& HAMMEL (1990), são as competências essenciais, exprimi uma dimensão organizacional de competências. Em seguida conceitua-se as competências funcionais, necessárias ao desenvolvimento das áreas vitais da empresa. E as competências individuais, onde se destacam as competências gerenciais, que participam na formação das outras dimensões das competências organizacionais

Concordando com FLEURY \& FLEURY (2001), RUAS (2001) afirma que o conceito de competência perpassa pelos verbos saber (conhecimento), saber-fazer (habilidades), mas vai muito além disso, pois envolve o saber ser/ agir (atitudes). A competência surge a partir da aplicação do saber num contexto específico, delimitado por uma cultura institucional, por relações de trabalho singulares, condições temporárias e recursos reduzidos. Sendo assim, segundo o autor, a competência só existe no ato e não no vazio. É a oportunidade de experimentar e aprender a lidar com novos desafios, projetos e problemas e conseqüentemente desenvolver as próprias competências necessárias ao contexto organizacional atual.

Conforme descrito acima, a noção de competência pode ser analisada a partir de várias abordagens e de várias correntes de estudo (americana, latino-americana, francesa, australiana). Em resumo pode-se concluir que a idéia de competência tem surgido como uma forma de reconsiderar e propor novos padrões de interação entre as pessoas, seus saberes e capacidades e às organizações e suas demandas devido as intensas mudanças qualitativas ocorridas nas últimas décadas nos processos de trabalho essenciais e relacionais (relações com os clientes, fornecedores e com os próprios trabalhadores). Este contexto difuso acaba por exigir novas formas de pensar, de agir e de traçar novas e diferentes competências individuais, que vão retratar as competências gerenciais (RUAS 2001). 
Para a presente pesquisa, foi utilizado o conceito de competência construído por FLEURY \& FLEURY (2001:21) ou seja; competência será compreendido como:

“...um saber ágil responsável e reconhecido, que implica saber mobilizar, integrar, transferir conhecimentos, recursos, habilidades, que agreguem valor econômico à organização e social ao indivíduo, com ênfase na ação e no resultado".

\section{Pesquisa de Campo}

Este item focaliza os resultados da pesquisa desenvolvida com o objetivo de identificar quais as competências existentes e as requeridas no trabalho dos gestores da Igreja Metodista, no desempenho das suas funções. O universo da pesquisa foi composto pelo grupo de pastores da Igreja Metodista, que têm cargo de superintendentes distritais, no total de 93.

Foi realizado um survey com propósito exploratório, visando obter respostas susceptíveis à análise quantitativa e qualitativa. O questionário, instrumento básico da pesquisa, foi elaborado a partir do conceito de Competência Profissional desenvolvido por FLEURY \& FLEURY (2001:21). As questões, no total de 51, foram desenvolvidas, pelos autores deste artigo, a partir do significado das sete variáveis deste modelo.

A primeira parte do questionário foi constituída por questões que investigam os dados demográficos, ocupacionais e pessoais dos participantes. A segunda parte foi estruturada em três blocos de forma a facilitar a compreensão por parte dos respondentes: $O$ primeiro bloco de questões foi concentrado na análise da lgreja Metodista como um todo. O segundo bloco foi concentrado no trabalho dos superintendentes distritais e o terceiro bloco no trabalho dos superintendentes distritais com os pastores. Na segunda parte do questionário foi utilizada a escala do tipo Likert, que estabelece cinco níveis de resposta, variando do "discordo totalmente" ao "concordo totalmente".

Como forma de coletar mais informações dos respondentes e propiciar também uma avaliação qualitativa, foi deixado um espaço no questionário, para que os pesquisados pudessem incluir sugestões e informações complementares que julgassem pertinentes, frente aos temas tratados. Os questionários foram enviados pelos correios no início do mês de novembro de 2002.

\section{Análise e Interpretação dos Resultados}

Este capítulo tem o objetivo de analisar, com base na pesquisa de campo, quais as competências que estão sendo utilizadas e quais as requeridas para o trabalho dos gestores da Igreja Metodista no Brasil. Esta análise ficou estruturada da seguinte forma: na $1^{\text {a }}$ parte foi feita a caracterização da amostra estudada e na $2^{\underline{a}}$ parte a amostra foi analisada com base no modelo de Competências Profissionais proposto por FLEURY \& FLEURY (2001). 


\section{Caracterização da população e da amostra}

Do total de 93 questionários enviados, foram recebidos 58 , correspondendo a $62,4 \%$ do universo pesquisado.

Em termos de faixa etária, observou-se que a maioria dos superintendentes distritais possui mais de 45 anos $(53,4 \%)$. O percentual restante é composto por pastores que se situam numa faixa etária entre 36 a 45 anos (31\%) e na faixa etária de 26 a 35 anos $(15,5 \%)$.

Em relação ao estado civil, foi constatado que a grande maioria dos respondentes é casada (89.7\%), os solteiros e os desquitados/ divorciados totalizam apenas $10,3 \%$.

Quanto à distribuição por sexo, a população se caracteriza por ser formada por $86 \%$ masculina e $14 \%$ feminina. Esta mesma distribuição pode ser observada na amostra, onde houve um predomínio do masculino $(86,2 \%)$, uma vez que o sexo feminino obteve uma percentagem de $13,8 \%$.

O número reduzido de mulheres exercendo a função de superintendentes distritais é fator de preocupação para a Igreja Metodista no Brasil, que desde 1997, tem como uma das suas ênfases e diretrizes do seu Plano Nacional criar "....ações que criem condições para a efetiva participação das mulheres nos diferentes ministérios da Igreja, inclusive garantindo, obrigatoriamente, a sua participação nos órgãos decisórios da Igreja." (Religar, 1997)

No que se refere ao grau de escolaridade dos pesquisados, $57 \%$ possui somente 0 superior completo. Dos $43 \%$ restante da amostra, $19 \%$ já cursaram uma pós-graduação, seja em nível de especialização, mestrado ou doutorado e $24 \%$ apesar de já terem ingressado na pós-graduação (especialização, mestrado ou doutorado), ainda não concluíram.

A análise do grau de escolaridade é preocupante e merece destaque, pois mais da metade da amostra (57\%) não tem nenhum curso de pós-graduação, o que pode dificultar o estabelecimento de uma cultura focada na aprendizagem continuada. Este fato se torna relevante pois, conforme ressaltado no referencial teórico, para o desenvolvimento de competências é necessário fortalecer o processo de aprendizagem, que vai propiciar a transformação do conhecimento em competência.

Em relação ao tempo em que os pesquisados estão trabalhando no pastorado, a maioria dos superintendentes distritais (56\%), possui 21 anos ou mais de ministério pastoral. Dos $44 \%$ restantes, $22 \%$ têm de 5 a 10 anos e $20 \%$ de 11 a 20 anos.

A maioria (59\%) dos respondentes exerce a função de superintendente distrital há 5 anos ou mais; $9 \%$ atuam há menos de 1 ano e 33\% já exercem a função entre 1 a 4 anos.

Com relação ao tempo de graduação em Teologia, a maioria dos entrevistados (52\%) tem mais de 21 anos de conclusão do bacharelado em Teologia, enquanto que $31 \%$ têm até 10 anos de formado. Os $17 \%$ restantes possuem de 11 a 20 anos de graduação. 
Análise da amostra pesquisada com base no modelo de Competências Profissionais

Ao examinar o comportamento da amostra pesquisada frente ao modelo de Competências Profissionais adotado, pôde-se observar que as variáveis do modelo apresentaram médias que se situaram entre os valores 3,33 e 3,71, numa escala de 1 a 5, que é a escala de Likert (Tab. 5).

\section{TABELA 5}

Análise das variáveis do modelo de Competências Profissionais

\begin{tabular}{|c|c|c|c|c|c|c|c|}
\hline Variáveis & $\begin{array}{c}\text { Casos } \\
\text { válidos }\end{array}$ & Máximo & |Mínimo & $\begin{array}{l}\text { desvio } \\
\text { padrão }\end{array}$ & \begin{tabular}{|c} 
limite \\
inferior
\end{tabular} & média & $\begin{array}{c}\text { limite } \\
\text { superior }\end{array}$ \\
\hline Saber Agir & 56 & 4,67 & 2,33 & 0,53 & 3,19 & 3,33 & 3,47 \\
\hline Saber Mobilizar & 56 & 4,83 & 2,33 & 0,58 & 3,51 & 3,66 & 3,82 \\
\hline Saber Aprender & 55 & 4,58 & 2,42 & 0,43 & 3,24 & 3,36 & 3,47 \\
\hline Saber Comprometer-se & 56 & 4,44 & 2,44 & 0,49 & 3,37 & 3,50 & 3,63 \\
\hline Saber Assumir Responsabil. & 54 & 5,00 & 2,33 & 0,58 & 3,59 & 3,75 & 3,91 \\
\hline Ter Visão Estratégica & 54 & 4,86 & 2,57 & 0,49 & 3,58 & 3,71 & 3,84 \\
\hline Saber Comunicar & 57 & 4,11 & 2,22 & 0,44 & 3,26 & 3,37 & 3,49 \\
\hline
\end{tabular}

FONTE- Dados obtidos na pesquisa.

Devido à grande concentração dos valores encontrados, isto é, todos ficaram entre os números 3,0 e 4,0 e visando obter uma maior discriminação na análise destas variáveis, o valor de referência adotado para a análise foi 3,60, isto é, $20 \%$ maior do que o valor 3,0 que é a média da escala Likert. As variáveis foram, portanto, classificadas em dois grupos: aquelas que obtiveram médias acima de 3,60 foram consideradas como tendo resultados satisfatórios e aquelas com média abaixo de 3,60 foram consideradas como necessitando de melhoria.

Com base nos critérios definidos no parágrafo anterior, pode-se observar que as variáveis Saber Mobilizar (3,66), Ter Visão Estratégica $(3,71)$ e Saber Assumir Responsabilidades $(3,75)$, tiveram avaliação positiva, uma vez que apresentaram uma média maior que 3,60, enquanto as variáveis Saber Agir $(3,33)$, Saber Aprender $(3,36)$, Saber Comunicar $(3,37)$ e Saber Comprometer-se $(3,50)$ demonstraram um resultado insatisfatório, inferior a 3,60. Estes resultados podem ser visualizados no GRAF 1.

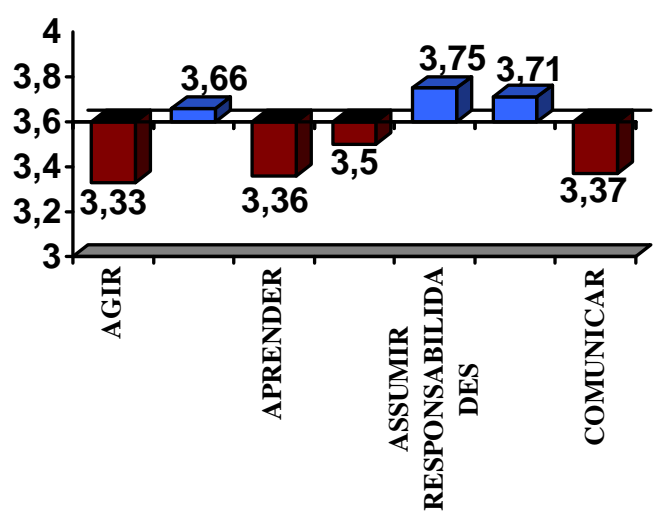

GRÁFICO 1 - Análise das variáveis do modelo de Competências Profissionais adotado FONTE - Dados obtidos na pesquisa. 


\section{Variáveis que obtiveram resultados considerados insatisfatórios}

São feitos a seguir alguns comentários sobre cada uma destas variáveis.

Variável Saber Agir: Saber o que e por que faz. Saber julgar, escolher, decidir

Em relação à competência Saber Agir, os depoimentos de três (3) dos pesquisados sinalizam possíveis causas do resultado insatisfatório:

"O poder é muito centralizado no bispo."

"Creio que se faz necessário uma melhor preparação dos superintendentes distritais (SD's). Melhor definição canônica de seu papel, mais recursos financeiros e mais autonomia..."

"Acredito que estamos em processo de aprendizado do que é ser um SD. Isto é, o SD é um representante do bispo aos pastores e igrejas ou representantes das igrejas e pastores ao bispo, ou mesmo os dois?"

Os depoimentos sinalizam que, a falta da definição clara do papel do SD, possa estar dificultando o processo de julgamento, escolha e tomada de decisões pertinentes à função de superintendentes. Sugere-se a revisão das práticas relativas ao processo decisório na Igreja Metodista, de modo a torná-lo mais participativo e ágil, bem como, uma melhor definição do papel do superintendente distrital.

Variável Saber Aprender: Trabalhar o conhecimento e a experiência. Rever modelos mentais. Saber desenvolver-se e propiciar o desenvolvimento dos outros.

Dentre as competências profissionais, o "Saber Aprender" demonstra a necessidade do indivíduo saber desenvolver-se e propiciar o desenvolvimento dos outros, de forma contínua. Uma primeira análise sinaliza a necessidade do desenvolvimento da competência profissional - "Saber Aprender" - onde a instituição precisa estabelecer uma cultura que privilegia programas de educação continuada visando o desenvolvimento de competências profissionais dos superintendentes distritais da Igreja Metodista no Brasil.

A função de superintendente distrital exige varias habilidades, que vão além do trabalho com a fé. O superintendente distrital exerce uma duplicidade de papéis, ora são supervisores, onde necessitam utilizar técnicas da administração, ora eles são pastores, trabalhando mais com a Teologia. Se esta duplicidade de papéis não for bem desenvolvida, orientada e qualificada, pode ser um dificultador para exercer com eficácia o cargo de superintendente distrital. distritais:

Essa necessidade se faz presente no comentário de um dos superintendentes

"Creio que se faz necessário um melhor preparo dos Superintendentes distritais. Melhor definição canônica do seu papel..."

Um dos superintendentes distritais conseguiu traduzir em palavras essa duplicidade do papel do supervisor:

“... o superintendente distrital exerce atividades de supervisão e pastorais, ou seja, ele bate e assopra, funções difíceis de serem conjugadas pela mesma pessoa." 
FLEURY \& FLEURY (2001) afirmam que o primeiro nível para o processo de aprendizagem organizacional é o nível do indivíduo. Esse fato se torna relevante ao ser relacionado com os dados da faixa etária, pois mais da metade da amostra $(53,4 \%)$ tem mais de 45 anos e mais da metade da amostra também se caracterizou por não ter nenhum curso de pós-graduação. O que sugere uma amostra de pessoas que obtiveram a graduação e não desenvolveu o seu processo de aprendizagem continuada.

Do total de respondentes, $57 \%$ já realizaram algum curso, não acadêmico, que visa o desenvolvimento para exercer a função de superintendente distrital. Este dado vem a corroborar com a análise do item anterior, pois quase a metade dos pesquisados (43\%) não realizou nenhum curso para 0 aprimoramento das suas funções como superintendente distrital.

A declaração de um dos pesquisados indica que a prática do reconhecimento não faz parte da cultura da organização. Um dos superintendentes demonstrou esta insatisfação no seu relato.

"Na lgreja Metodista e em nossa região não há premiação e nem motivação quando se faz um bom trabalho como SD ou como pastor local."

A necessidade de esquemas de reconhecimento e premiação tem sido apontada por vários autores (ADIZES, 1998; TERRA, 2001), como sendo fundamentais para a criação de ambientes de aprendizagem. As idéias precisam ser valorizadas e respeitadas, as realizações dos funcionários precisam ser comemoradas. Este apoio dos gestores promove o encorajamento, que por sua vez, contribuem para a inovação e a criatividade das pessoas no ambiente de trabalho. Os resultados encontrados sugerem a necessidade, da criação de mecanismos de valorização, reconhecimento e até de premiação pelo desempenho e contribuições destes profissionais para com 0 desenvolvimento do trabalho.

Os resultados não muito significativos em relação à aprendizagem individual e conseqüentemente à aprendizagem organizacional, que estão relacionados à competência saber aprender, indica que a Igreja precisa rever as suas práticas para a ação de aprendizagem, de modo a permitir o desenvolvimento de competências e mudanças, que garantam um constante aperfeiçoamento de sua base de conhecimento.

Estes fatores se mostram significativos, pois de acordo com NONAKA \& TAKEUCHI (1998) os gestores organizacionais precisam criar ambientes para que os indivíduos possam exercer todo o seu potencial criativo e reverter tudo isso para os estoques de conhecimento organizacional. No âmbito da Igreja esta abertura é fundamental, devido ao momento de grandes questionamentos na ideologia de diversos grupos religiosos, sobre o risco de perda da sua identidade e missão.

Variável Saber Comunicar: Compreender, processar, transmitir informações e conhecimentos, assegurando o entendimento da mensagem pelos outros.

Foi possível identificar uma dificuldade na comunicação entre as igrejas do distrito. Esta observação fica bem evidenciada no relato de um dos pesquisados: 
"Falta cumprir nas igrejas dos distritos a nossa tão falada e valorizada nos documentos da nossa Igreja - conexionalidade. Nosso trabalho tem sido muito estanque. Tem havido um processo muito grande de congregalização das nossas igrejas. Infelizmente!"

Esta afirmativa evidencia uma carência de trabalhos que aproximem o trabalho dos SD's com a sua equipe de pastores. Sugere-se uma ação, por parte dos superintendentes distritais, em desenvolver nos seus distritos uma cultura, que estimule os seus pastores a compartilharem com o grupo as suas experiências. É importante ressaltar a possível ligação desse resultado com o analisado na competência "Saber Aprender", em relação aos esquemas de premiação, reconhecimento e valorização por resultados e contribuições para o distrito. Será que a falta de estímulo e reconhecimento está levando as pessoas a se calarem?

Este indicador é relevante, pois conforme o modelo de criação do conhecimento elaborado por NONAKA \& TAKEUCHI (1997:69), a socialização do conhecimento e o compartilhamento de experiências, representam os primeiros passos para a produção do conhecimento organizacional, pois "Sem alguma forma de experiência compartilhada, é extremamente difícil para uma pessoa projetar-se no processo de raciocínio do outro indivíduo." Diversos outros estudiosos sobre Aprendizagem nas organizações concordam com as idéias de NONAKA \& TAKEUCHI (1997) e ressaltam a importância da troca de experiências, para a criação do conhecimento tácito.

Variável Saber Comprometer-Se: Saber engajar-se e comprometer-se com os objetivos da organização.

Em relação à competência saber comprometer-se, foi observada uma avaliação insatisfatória devido principalmente a três questões que estão bem correlacionadas entre si. Esta avaliação pode ser feita com base nos resultados das questões abaixo:

- A prática da ética é prioridade dentro da Igreja Metodista, apenas $34,5 \%$ dos respondentes concordaram com esta afirmação.

- No seu distrito, há reuniões freqüentes para o estudo e a reflexão da ética no ministério pastoral, apenas $36,2 \%$ dos respondentes concordaram com esta afirmação.

- No seu distrito, há reuniões freqüentes para o estudo dos documentos da igreja metodista apenas $29,3 \%$ dos respondentes concordaram com esta afirmação.

Percebe-se um nível baixo de concordância em relação a um tema tão importante para a vida da instituição que é a ética e o conhecimento dos documentos da lgreja. A falta de conhecimento dos documentos da Igreja, nos quais estão as diretrizes, missão, costumes, valores, rituais a serem seguidos, merece atenção, pois pode levar a perda da Identidade Metodista e da sua finalidade, desvirtuando-se de suas marcas essenciais, o que acaba criando grupos isolados, com práticas divergentes do contexto da instituição.

\section{Variáveis que obtiveram os resultados satisfatórios}

Variável Saber Mobilizar: Saber mobilizar recursos de pessoas, financeiros, materiais, criando sinergia entre eles.

No que se refere a Saber Mobilizar, as questões que mais se destacaram positivamente foram: 
- Na sua região, existe um esquema organizado que permite a todos os SDs contribuírem sistematicamente com idéias e sugestões para a melhoria do trabalho regional. $69 \%$ dos pesquisados concordaram com esta afirmação.

- O trabalho do seu distrito é feito de modo a mobilizar a participação de todos e fortalecer o trabalho em equipe. $65 \%$ dos pesquisados concordaram com esta afirmação.

O desenvolvimento desta habilidade é muito positivo para o trabalho da Igreja, pois conforme AGOSTINHO (2002) a convivencialidade pode ser uma forma de enfrentar crises. "A partir do momento em que um padrão de interação convivencial se estabelece, abrem-se os canais para que o conhecimento flua e se reconstrua" (AGOSTINHO, 2002:29).

Variável Ter Visão Estratégica: Conhecer e entender o negócio da organização, seu ambiente, identificando oportunidades, alternativas

As questões que mais contribuíram para a avaliação positiva desta variável foram:

- O planejamento distrital é elaborado de forma participativa com os/as pastores/as de modo que todos os/as pastores/as desenvolvam os objetivos comuns para o distrito. $70 \%$ dos pesquisados concordaram com esta afirmação.

- Entre os membros da sua equipe de pastores/as existe um ambiente descontraído, que propicie o bom humor entre o grupo. $81 \%$ dos pesquisados concordaram.

Este resultado mostra-se coerente com a avaliação positiva sobre o ambiente descontraído existente na Igreja, feita na competência "Saber Aprender". Pode-se inferir que o clima positivo da equipe regional de SDs, acaba por possibilitar um ambiente positivo desses SDs com os seus respectivos pastores em cada distrito.

Variável Saber Assumir Responsabilidades: Ser responsável, assumindo os riscos e as conseqüências de suas ações, e ser, por isso, reconhecido.

As questões que merecem destaque são:

- Os/as pastores/as do seu distrito assumem naturalmente as responsabilidades e as conseqüências de suas ações no trabalho da igreja local. 60\% dos pesquisados concordaram com esta afirmação.

- Você se sente reconhecido pelos/as pastores/as do seu distrito e pelo/ pela seu/ sua bispo/bispa da sua região pela responsabilidade assumida perante as suas tarefas como SD. $77,6 \%$ dos pesquisados concordaram com esta afirmação.

Fica claro nestas questões que grande parte dos superintendentes distritais, responderam estar assumindo naturalmente os riscos e as conseqüências de suas ações.

\section{Conclusões}

O presente trabalho foi desenvolvido com o objetivo de efetuar um diagnóstico das práticas gerenciais da Igreja Metodista no Brasil, segundo o conceito de Competências Profissionais de FLEURY \& FLEURY (2001). Para atingir este objetivo, foi desenvolvido um questionário, com 51 questões estruturadas, usando a escala tipo Likert, além de uma 
questão aberta, para receber sugestões, críticas e comentários pertinentes aos temas tratados, possibilitando assim uma análise também qualitativa.

A instituição pesquisada foi a Igreja Metodista no Brasil, onde a amostra foi focada no grupo de pastores desta organização, que possuem cargo gerencial. Estes são denominados de superintendentes distritais - SDs.

Do total de 93 questionários enviados, foram recebidas 58 respostas $(62,4 \%)$. A amostra se caracterizou por uma população basicamente masculina. Ressalta-se 0 número reduzido de mulheres exercendo a função de superintendente distrital na Igreja Metodista, apenas $14 \%$ do total. Outro fator relevante apresentado pela amostra refere-se ao fato de mais da metade dos superintendentes distritais possuírem idade acima de 45 anos, já terem se graduado há mais de 21 anos em teologia e só possuírem o curso superior. Estes profissionais não deram continuidade ao processo de educação continuada, nem mesmo com cursos não acadêmicos, que possibilitem 0 aperfeiçoamento das práticas, para exercer a função de SDs.

Das sete variáveis do modelo de competência adotado para análise, três variáveis foram consideradas satisfatórias que foram: "Saber Mobilizar", "Ter Visão Estratégica" e "Saber Assumir Responsabilidades". Quatro variáveis foram consideradas com resultados insatisfatórios e necessitando, portanto, de ações da Igreja Metodista, visando a sua melhoria. Estas variáveis foram: "Saber Agir", "Saber Aprender", "Saber Comprometer-se" e "Saber Comunicar".

Alguns depoimentos dos respondentes demonstram uma falta de clareza quanto ao papel do superintendente distrital, o que pode estar dificultando o processo de julgamento e de tomada de decisões. Essa constatação revela a necessidade de rever as práticas do processo decisório da Igreja Metodista, bem como uma definição mais clara do papel dos SDs.

Os resultados encontrados também sugerem a necessidade da criação de mecanismos de valorização, reconhecimento e até de premiação aos SDs, em relação ao desenvolvimento do trabalho, que, conforme já ressaltado por vários autores, contribui para a criação de ambientes de aprendizagem.

Em relação à comunicação, pôde-se identificar a necessidade de desenvolvimento de uma cultura que estimule práticas de compartilhamento de experiências e de trabalho em grupo. As deficiências na comunicação foram ressaltadas pelas manifestações de alguns dos pesquisados, que lamentaram o isolamento do trabalho do SD e a falta da tão discutida conexionalidade.

A análise feita em relação ao investimento na capacitação profissional e pessoal, veio confirmar os indícios levantados na caracterização da amostra, quanto à necessidade de incentivos às práticas de aprendizagem contínua. Com base no percentual significativo de $43 \%$ dos pesquisados, que não freqüentaram até hoje nenhum curso de aprimoramento e considerando a natureza da tarefa dos superintendentes distritais e o perfil do trabalhador multidisciplinar demandado pelo mundo atual, que é de um profissional com múltiplas habilidades, executando tarefas variadas e com maior possibilidade de auto controle, questiona-se se estes profissionais estão preparados para atender a complexidade de suas tarefas na atualidade. Este ponto foi ressaltado pelos próprios pesquisados. 
Merece destaque a avaliação positiva quanto ao comprometimento e engajamento da equipe regional de superintendentes distritais e a equipe distrital de pastores, para com as suas funções. Outro ponto relevante foi a existência de um ambiente descontraído na equipe regional de superintendentes distritais, fundamental às organizações criativas.

Acredita-se que a relevância maior da pesquisa está na tentativa de se estabelecer um estudo de exploração inicial das competências requeridas pelos gestores da organização pesquisada, fornecendo alternativas para o desenvolvimento dos indivíduos e da organização, bem como abrir caminhos para estudos posteriores. Essa proposição reforça, acima de tudo, os próprios propósitos da Igreja Metodista.

\section{Referências Bibliográficas}

1.ADIZES, Ichak. É Preciso Mudar Antes. HSM Management, São Paulo, n. 11, p. 6468, nov.-dez. 1998.

2.AGOSTINHO, Márcia Esteves. Aprendizado Coletivo como Resposta a Crises. In: AGOSTINHO, Márcia Esteves; BAUER, Ruben; PREDEBON, José (Orgs). Convivencialidade: a expressão da vida nas empresas. São Paulo: Atlas, 2002. p. 27- 30.

3.BARBOSA, Allan Claudius Queiroz. Gestão de competências em organizações: um mosaico das experiências em Mias Gerais. In: ENANPAD, 25, Campinas, set. 2001. Anais Eletrônicos, Rio de Janeiro: ANPAD, 2001.

4.Cânones da Igreja Metodista 2002. São Paulo: Editora Cedro, 2001

5.DUTRA, Joel Souza. Gestão de Pessoas com Base em Competências. In: DUTRA, Joel Souza. Gestão por Competências: um novo modelo avançado para o gerenciamento de pessoas. $2^{\mathrm{a}}$ ed. São Paulo: Editora Gente, 2001. p. 25-43.

6.FLEURY, Afonso; FLEURY Maria Tereza Leme. Estratégias Empresariais e Formação de Competências: um quebra-cabeça caleidoscópico da indústria brasileira. São Paulo: Atlas, 2001.

7..HIRATA, H. Da polarização das qualificações ao modelo de competência. IN: FERRETI, C. (org.). Novas Tecnologias, Trabalho e Educação. Petrópolis: Vozes, 1994.

8.LE BOTERF, G. De la compétence. Paris: Les Editions d' Organization, 1994

9. NONAKA, I; TAKEUCHI, H. Criação de Conhecimento na Empresa. Rio de Janeiro: Campus, 1998.

10. MCLAGAN, P A. Competencies: the next generation. Training and development, $p$. 40-47, May 1997

11. PRAHALAD \& HAMMEL. The core competence of the corporation. Harvard Business Review, v.68, no 3, p. 79-91, May/ June 1990.

12. RELIGAR. Área Geral Da Igreja Metodista. № 4, dez. 1997.

13. RUAS, Roberto. Desenvolvimento de competências gerenciais e contribuição da aprendizagem organizacional. In: FLEURY, Maria Tereza; OLIVEIRA JÚNIOR, Moacir de Miranda (Orgs). Gestão Estratégica do Conhecimento: integrando aprendizagem, conhecimento e competências. São Paulo: Atlas, 2001. p. 242- 269.

14. TERRA, José Cláudio C. Gestão do Conhecimento o Grande Desafio Empresarial: uma abordagem baseada no aprendizado e na criatividade. São Paulo: Negócio Editora, 2001.

15.ZARIFIAN, P. Compétences et organization qualifiante em mileu industriel. IN: MINET, Francis; PARLIER, Michel; WITTE, Serge. La competénce: mtthe, construction ou realité? Paris: Liasons, 1994.

16. Gestão da e pela Competência. Seminário Internacional: Educação

Profissional, Trabalho e Competências. Rio de Janeiro: 1996. (mimeo). 
17. Das Mutações do Trabalho À Competência. In: ZARIFIAN, P. Objetivo Competência: por uma nova lógica. São Paulo: Atlas, 2001. cap. 2, p. 36 - 65. 